\title{
Commentary: A hybrid strategy for extracorporeal membrane oxygenation to ventricular assist device transition: Is doing less more?
}

\author{
Jason J. Han, MD, and Pavan Atluri, MD
}

\footnotetext{
From the Division of Cardiovascular Surgery, Department of Surgery, University of Pennsylvania, Philadelphia, $\mathrm{Pa}$.

Disclosures: Authors have nothing to disclose with regard to commercial support.

Received for publication Nov 20, 2018; accepted for publication Nov 21, 2018; available ahead of print Dec 28 , 2018.

Address for reprints: Pavan Atluri, MD, Division of Cardiovascular Surgery, Hospital of the University of Pennsylvania, 3400 Spruce St, 6 Silverstein Pavilion, Philadelphia, PA 19104 (E-mail: Pavan.Atluri@uphs.upenn. edu).

J Thorac Cardiovasc Surg 2019;158:e11-2

$0022-5223 / \$ 36.00$

Copyright (C) 2018 by The American Association for Thoracic Surgery

https://doi.org/10.1016/j.jtcvs.2018.11.071
}

Venoarterial extracorporeal membrane oxygenation (VAECMO) is a well-established mode of mechanical circulatory support for patients with cardiopulmonary collapse. With rapid peripheral initiation, it can restore perfusion and oxygenation effectively, mitigate further end-organ injuries, and serve as a bridge to a more durable platform. ${ }^{1}$ In our experience, nearly $80 \%$ of patients who were rescued with VA-ECMO before transitioning to ventricular assist 1 year. $^{2}$ Despite its lifesaving potential, however, VA-ECMO is also known to cause a wide range of complications, especially with prolonged use, which can prevent stabilization necessary to transition to the next platform. ${ }^{2}$ In this issue of the Journal, Quan and colleagues ${ }^{3}$ describe one such challenge, the case of a young patient who had severe refractory pulmonary edema develop in the setting of increased afterload on the left side of the heart, with consequent pressure overload and distension.

Various strategies to reduce left ventricular distension in this setting have been reported previously, such as adding a left ventricular vent or placing an Impella device (Abiomed, Danvers, Mass) to augment native output. ${ }^{4,5}$ Each of these strategies is associated with its own set of complexities and potential complications. The experience of Quan and colleagues $^{3}$ in carrying out a percutaneous atrial septostomy to create an efficient left-to-right shunt in this scenario, which successfully reduced the left atrial pressure by more than $50 \%$ and eliminated the pulmonary edema, epitomized the less-is-more principle that is important in treating this patient population. ${ }^{6,7}$ It was the least invasive and least traumatic intervention, which was nonetheless perfectly adequate in creating an opportunity for weaning from VA-ECMO and for VAD implantation. Furthermore, in using a hybrid operating room to close the septostomy device (VAD) or heart transplantation were alive at

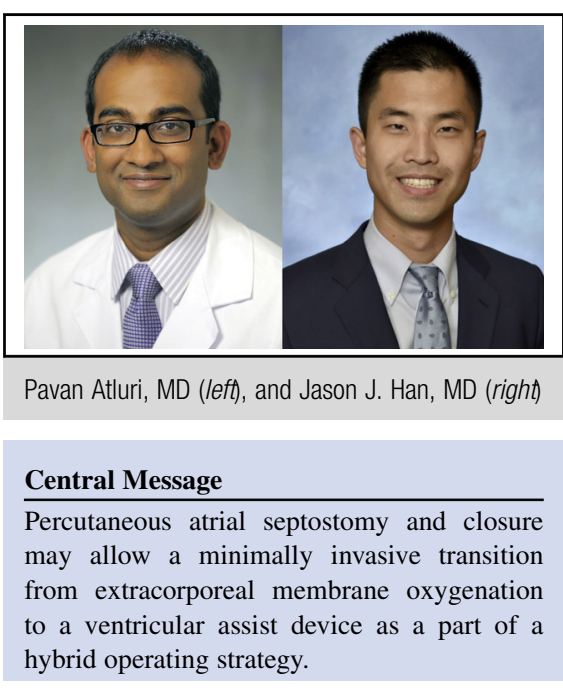

See Article page e7. percutaneously, Quan and colleagues ${ }^{3}$ were also able to retain a minimally invasive approach during VAD implantation, although the benefits in this critically ill population remain to be further explored.

Despite its efficacy in this report, however, it is too early to consider percutaneous atrial septostomy and subsequent closure broadly among patients with inadequate decompression on VA-ECMO. It should only be judiciously applied in settings where the patient requires a stopgap measure to bridge to a more durable platform without any other significant contraindications. Otherwise, its benefit in terms of prognosis will be limited. In addition, the additive cost of an Amplatzer device (St Jude Medical, St Paul, Minn), as opposed to the inexpensive surgical closure, ought to be given adequate consideration. In an era of rising health care costs, the overall impact of concomitant procedures on the margins of VAD implants should be considered in our attempts to expand the application of destination mechanical circulatory support therapy widely.

Quan and colleagues ${ }^{3}$ are to be congratulated for their innovative approach with an excellent outcome. By incorporating percutaneous expertise into traditional bridge strategies, they were able to rescue a patient in severe respiratory failure refractory to VA-ECMO support without adding any significant surgical trauma. Their report further affirms percutaneous atrial septostomy and subsequent 
closure as an important component of a multifaceted strategy for stabilization of select patients on VA-ECMO and heralds a promising era of increasing intersections between the field of transcatheter interventions and mechanical circulatory support.

\section{References}

1. Unai S, Yamane K, Tanaka D, Cook G, Hirose H, Cavarocchi NC, et al. Quality of life and mid-term survival of patients bridged with extracorporeal membrane oxygenation to left ventricular assist device. ASAIO J. 2017;63:273-8.

2. Han JJ, Chung J, Chen CW, Gaffey AC, Sotolongo A, Justice C, et al. Different clinical course and complications in Interagency Registry for Mechanically Assisted Circulatory Support 1 (INTERMACS) patients managed with or without extracorporeal membrane oxygenation. ASAIO J. 2018;64:318-22.
3. Quan W, Shah A, Feller E, Ton VK, Vesely M, Sorensen E, et al. Transcatheter closure of atrial septostomy facilitates minimally invasive left ventricular assist device implantation. J Thorac Cardiovasc Surg. 2019;158:e7-9.

4. Patel SM, Lipinski J, Al-Kindi SG, Patel T, Saric P, Li J, et al. Simultaneous venoarterial extracorporeal membrane oxygenation and percutaneous left ventricular decompression therapy with Impella is associated with improved outcomes in refractory cardiogenic shock. ASAIO J. February 27, 2018 [Epub ahead of print].

5. Cheng A, Swartz MF, Massey HT. Impella to unload the left ventricle during peripheral extracorporeal membrane oxygenation. ASAIO J. 2013;59:533-6.

6. Lin YN, Chen YH, Wang HJ, Hung JS, Chang KC, Lo PH. Atrial septostomy for left atrial decompression during extracorporeal membrane oxygenation by Inoue balloon catheter. Circ J. 2017;81:1419-23.

7. Prasad A, Ghodsizad A, Brehm C, Kozak M, Körner M, El Banayosy A, et al. Refractory pulmonary edema and upper body hypoxemia during veno-arterial extracorporeal membrane oxygenation-a case for atrial septostomy. Artif Organs. 2018;42:664-9. 